\title{
An Impact of the Variable Technological Progress Rate on the Trajectory of Labor Productivity
}

\author{
Monika Bolińska ${ }^{1}$, Pawel Dykas ${ }^{1}$, Grzegorz Mentel $^{2}$, Tomasz \\ Misiak $^{3}$
}

${ }^{1}$ Department of Mathematical Economics, The Faculty of Management and Social Communication, Jagiellonian University in Cracow, Prof. Stanisława

Łojasiewicza 4 St., 30-348 Cracow, e-mail: monika.bolinska@doctoral.uj.edu.pl; pawel.dykas@uj.edu.pl

${ }^{2}$ Department of Quantitative Methods, Faculty of Management, Rzeszow University of Technology, Powstancow Warszawy 12 St., 35-959 Rzeszow, email: gmentel@prz.edu.pl

${ }^{3}$ Department of Economics, Faculty of Management, Rzeszow University of Technology, Powstancow Warszawy 12 St., 35-959 Rzeszow, e-mail: tmisiak@prz.edu.pl

\footnotetext{
Abstract: The goal of this paper is to develop the neo-classical Solow growth model, in which, the authors repeal an assumption of a constant rate of growth of technological progress. Herein, the authors assume an alternative trajectory of an increase in scientific and technical knowledge $A(t)$, and on that basis, they accept the following assumptions. First, the rate of growth of technological progress is not constant, but changes over time. Second, the path of the growth of the scientific and technological knowledge tends toward a certain level in the long term, which can be equated with the equivalent of the technological boundary. Such a modification of the assumptions regarding the technological progress rates, allows leading growth paths for both capital and product per unit of effective labor. Next, based on the solution of the presented growth model, the authors calibrated the parameters and carried out numerical simulations. Numerical simulations, conducted for the Polish economy in a 100-year horizon, allowed an inclusion of scenarios regarding both the rate of technological progress and investment rates. In the simulations, two variants of the annualized rates of technological progress were adopted (optimistic, $g=1.7 \%$ and realistic, $g=1.5 \%$ ). The adopted levels of technological progress rates were used to determine the horizontal asymptote for the scientific and technological knowledge $A(t)$ that will be shaped in accordance with geometric progress. In the considered variants the following investment rates were adopted: 15, 20 and 25\%. This allowed determining the trajectories of labor productivity growth in the Polish economy taking into account different combinations of changes in the rates of technological progress and investment rates.
} 
Keywords: trajectories of labor productivity; variable rates of technological progress; gamma function; numerical simulations

\section{Introduction}

In the theory of economics technological progress is considered as one of the most important factors determining economic growth. In growth models technological progress is perceived differently and there is a large variety of factors that generate progress, which undoubtedly affects its exogenous or endogenous character. Apart from the factors determining technological progress, in this article the authors attempt to develop the neo-classical growth Solow model. They repeal the assumption of a constant growth rate of technological progress. In the paper the authors assume an alternative trajectory of an increase in scientific and technological knowledge, and on its basis of they assume the following assumptions. Firstly, the growth rate of technological progress is not constant but changes over time. Secondly, the growth path of scientific and technological knowledge tends to a certain level in the long term, which can be equated with the equivalent of the technological boundary.

The structure of this paper is as follows. The first section is an introduction. The second part, a review of the literature regarding the inclusion of technological progress in selected models of economic growth and selected generalizations of the neo-classical Solow model were presented. The third part contains an analytical solution of the model that takes into account alternative assumptions regarding the development path of the scientific and technological knowledge. In the fourth part, the parameters of the presented model are calibrated and numerical simulations of labor productivity growth paths in the considered variants are presented. Part five is a summary of the considerations and the more important conclusions.

\section{Review of the Literature}

Economic growth is a multidimensional and long-term process leading to an increase of the production potential of a given economy. The multidimensional character of economic growth is primarily the result of many factors determining this process, and the basic ones include: capital, labor, technological progress, institutional factors or social capital [25, 27, 30]. Multidimensionality also results from an analysis of various aspects of particular factors that determine the processes of economic growth [26]. Capital in growth models is considered as material, human or social capital. Technological progress as an exogenous or endogenous factor, embodied or unmasked in a man, etc. A great contribution to 
the development of the theory of growth is attributed to the Solow [23] model which became the foundation for later growth models. The Solow model was based on the power production function of the Cobb-Douglas type and the equation of capital accumulation which determines its growth as investments in this capital reduced by its depreciated value. This model also assumed a constant income from the scale of the production process, a constant rate of technological progress, or a constant rate of increase in the number of employees [23]. The basic advantages of the Solow model include the form of the equation that describes the accumulation of tangible capital, an uncomplicated analytical form of the model solution, which, with the power production function, is easily empirically verifiable by determining the growth paths of technological labor or labor productivity. The main weaknesses of the model include, first of all, an adoption of physical capital as the only factor of production, thus omitting, for example, human capital, adopting permanent economies of scale and treating technological progress or the number of employees as exogenous variables (for more on the disadvantages and critiques of the Solow model [18] [19]. Criticism of the exogenous nature of technological progress in the Solow model made that many researchers attempted to endogenize a technological progress in growth models. One of the first researchers who presented the concept of endogenization of technological progress was Conlisk. In his research he accepted the assumption that economy and its growth are a closed system of dependencies between investment rates in human and material capital and technological progress [6]. Conlisk's assumptions were developed as part of a new growth theory in which the so-called Solow residual was understood as the result of expenditure in human capital, the product of which are new production techniques determining economic growth. Technological progress as a product of human capital was endogenized. As part of the new growth theory two main trends of research can be distinguished. In the first approach an increase in technological progress is the effect of the accumulation of knowledge. In the endogenization models of knowledge accumulation, the research sector ( $\&$ D sector) is introduced. Its purpose is to generate new knowledge, and thanks to it, a larger product can be obtained with a given capital and labor resource. Such an approach to the endogenization of technological progress occurred in works including: [3] [20] [11] [1] [28] and empirical studies in the works of, among others [16] [29] [14]. The second trend assumes that the accumulation of capital is of fundamental importance for growth, while capital is recognized more broadly, including human capital as the causative factor of technical progress. The models created under the second trend include, among others works: Romer [21], Barro [2], Mankiw, Romer, Weil [17] or Kramer, Thompson [15].

Theories of endogenous growth, although they justified the issue of generating technological progress, proved to be incapable of explaining the key empirical regularities in the processes of growth and development in various regions of the world during the last two millennia. In general, exogenous and endogenous theories are classified as non-uniform theories of economic growth. Currently, one 
of the most interesting and advanced theories is Unified Growth Theory - Oded Galor [9]. With regard to this theory, it can be said, that it belongs to neoclassical theories of endogenous growth. One of its main assumptions is an interaction between investments in human capital and technological progress which evoke the following spiral. Human capital generated faster technological progress, which in turn increased the demand for human capital, leading to increasing investments in children quality, which ultimately led to a decrease in demographic growth and, as a result, to a decline in the population. An increase in demand for human capital caused by technological progress eventually resulted in an increase in the quality of children's education at the expense of the number of children they have. Therefore, human capital also plays an important role here. It creates a faster technological progress but also determines the demand for human capital, which results in the growth of human capital while leading in highly developed economies to a decrease in the birth rate and population, and this becomes a new stimulus for a further technological progress. The technology growth rate in the Galor [9] model is defined as a function of the quality of education and a sufficiently large active population. However, it is not constant as in the Solow model but is subject to change. In addition, the technological boundary is possible, and in the Solow model technological progress tends to infinity.

Most growth models were based on certain weaknesses of the Solow model, such as the assumption of the exogenous nature of technological progress or the adoption of physical capital as the only factor of production, excluding human capital. Some researchers focused their attention on developing the Solow model by repealing rather unrealistic assumptions. An example of this may be the work where the assumption that there is a constant rate of employment growth (constituting a constant percentage of the exponentially growing population) exists. It means that the number of people working in the economy in the long run increases to infinity, which was dictated by the existence of a positive rate of demographic growth. Nowadays, demographic processes taking place in many developed economies undermine the accuracy of the above assumptions. The studies where alternative assumptions about the paths of employment growth are considered include the works: Guerrini [10] [12], Biancia, Guerrini [4], Sinnathurai [22], Sika, Vidová [24] or Dykas, Misiak, Mentel [7].

In this paper the authors attempt to develop the neo-classical Solow economic growth model and they repeal the assumption of a constant growth rate of technological progress. In the study the authors assume an alternative trajectory of an increase in scientific and technological knowledge, and on its basis they introduce the following assumptions. Firstly, the growth rate of a technological progress is not constant but changes over time. Secondly, the growth path of the scientific and technological knowledge tends to a certain level in the long term, which can be equated with the equivalent of the technological boundary. 


\section{Model}

The model of economic growth discussed in this paper is based on the following assumptions:

1) The production process is shaped according to the Cobb-Douglas [5] power production function according to the formula (see also: Tokarski $[27 ; 28])^{1}$ :

$$
Y(t)=(K(t))^{\alpha}(E(t))^{1-\alpha}
$$

where $Y$ is the stream of produced product, $K$ and $E$ are (respectively) capital expenditure and so-called the units of effective work, $\alpha \epsilon(0 ; 1)$ is the product's flexibility in terms of capital expenditure, and $1-\alpha \epsilon(0 ; 1)$ is the flexibility of the product created in the economy relatively to the units of effective work.

2) The accumulation of capital, as it is in the original Solow [23] model, is described by the following differential equation:

$\dot{K}(t)=s Y(t)-\delta K(t)$

where $\delta \epsilon(0 ; 1), s \epsilon(0 ; 1)$ mean (respectively) the investment rate and the rate of capital depreciation.

3) The amount of scientific and technological knowledge at the t moment is shaped according to the following growth path:

$$
A(t)=A_{0}-\theta e^{-\lambda t}
$$

where: $A_{0}-\theta>0$

The growth path of the scientific and technological knowledge described by equation (3) is characterized by the fact that in the infinite time horizon $(t \rightarrow \infty)$ this resource tends to the level of $A_{0}$. However, in the period $t=0$, the scientific and technological knowledge in the discussed model of economic growth is at the level $A_{0}-\Theta>0$. Moreover, by differentiating the relation (3) with respect to time, we obtain: $\dot{A}(t)=\theta \lambda e^{-\lambda t}>0$. The above dependences show that the growth path described by (3) grows asymptotically from level $A_{0^{-}} \Theta$ to the value A.

4) Effective work units $E(t)$ are defined as a set of scientific and technological knowledge $A(t)$ weighted by the number of employed $L(t)$. When determining the growth rate of units of effective work $\dot{E}(t) / E(t)$, it turns out that they grow at a growth rate equal to $n+g(t)$, where $n>0$ is the rate of growth in the number

\footnotetext{
${ }^{1}$ All subsequent macroeconomic variables are assumed to be differentiable functions of time $t \geq 0$. The record $x(t)$ will mean the value of the variable $x$ at the moment $t$, and $x(t)=d x / d t$ - the derivative of the variable $x$ after the time $t$, i.e. (economically speaking) an increase in the value of this variable at the moment $t$.
} 
of the employed in this economy, and $g(t)=\dot{A}(t) / A(t)$ is the growth rate of the scientific and technological knowledge referred to in the literature as technological progress rate. Hence and from dependence (3), it follows that the rate of technological progress in the discussed economic growth model is the following:

$$
g(t)=\frac{\theta \lambda e^{-\lambda t}}{A_{0}-\theta e^{-\lambda t}}
$$

From the above considerations, it follows that the growth rate of the effective work units is in line with:

$$
\frac{\dot{E}(t)}{E(t)}=\frac{\theta \lambda e^{-\lambda t}}{A_{0}-\theta e^{-\lambda t}}+n
$$

5) Assuming that $y=Y / L$ and $k=K / L$ are (respectively) labor productivity and technical development, then the following relationships will be satisfied:

$$
\begin{aligned}
& Y(t)=L_{0} e^{n t} y(t) \\
& K(t)=L_{0} e^{n t} k(t)
\end{aligned}
$$

6) Moreover, assuming that $y_{E}=Y / E$ and $k_{E}=K / E \quad y E=Y$ are (respectively) the stream of product produced and the capital stock per unit of effective work and based on equation (6) - (7) we get:

$$
\begin{aligned}
& y(t)=\left(A-\theta e^{-\lambda t}\right) y_{E}(t) \\
& k(t)=\left(A-\theta e^{-\lambda t}\right) k_{E}(t)
\end{aligned}
$$

From the production function (1) one can go to the production function in an intense form by dividing its sides by units of effective work $E>0$, which based on assumption 6) gives:

$$
y_{E}(t)=\left(k_{E}(t)\right)^{\alpha}
$$

The relation (10) describes the relationship between the capital expenditure per unit of effective work $\left(k_{E}\right)$ and the production volume per unit of work $\left(y_{E}\right)$.

Differentiating capital for the unit of effective work $\left(k_{E}=K / E\right)$ after the $\mathrm{t}$ time we obtain:

$$
\dot{k}_{E}(t)=\frac{\dot{K}(t) E(t)-K(t) \dot{E}(t)}{(E(t))^{2}}=\frac{\dot{K}(t)}{E(t)}-\frac{\dot{E}(t)}{E(t)} k_{E}(t)
$$

which together with (2)-(5) gives us:

$$
\dot{k}_{E}(t)=s y_{E}(t)-\mu(t) k_{E}(t)
$$


and $\mu(t)=\delta+g(t)+n>0$ means the rate of capital loss per unit of effective work. The differential equation (11) is equivalent to the Solow movement equation [22] in the economic growth model discussed here.

Taking into account the production function in the intense form (10) and the relation (11), one can obtain the following differential equation:

$\dot{k}_{E}(t)=s\left(k_{E}(t)\right)^{\alpha}-\mu(t) k_{E}(t)$

The equation (12) for each $t \geq 0$ has a trivial solution $\left(k_{E}(t)=0\right)$ and a family of nontrivial integrals ${ }^{2}$.

The equation (12) for $k_{E}>0$ can be presented as:

$$
\left(k_{E}(t)\right)^{-\alpha} \dot{k}_{E}(t)=s-\mu(t)\left(k_{E}(t)\right)^{1-\alpha}
$$

By making the Bernoullei substitution:

$$
z(t)=\left(k_{E}(t)\right)^{1-\alpha}
$$

we get the following transformation of the equation (13):

$$
\frac{\dot{z}(t)}{1-\alpha}=s-\mu(t) z(t)
$$

which can be transformed into the relation:

$$
\dot{z}(t)=(1-\alpha) s-(1-\alpha) \mu(t) z(t)
$$

Considering the homogeneous equation from the relation (15) we get:

$$
\dot{z}(t)=-(1-\alpha) \mu(t) z(t)
$$

the solution of equation (16) is given by the formula:

$$
z(t)=C(t) e^{-(1-\alpha)(\delta+n) t}(A(t))^{\alpha-1}
$$

where the factor $C(t)$ is the integral integration constant. Differentiating the equation (17) with respect to time and taking into account the relation (14) we get:

\footnotetext{
${ }^{2}$ The trivial integral (as uninteresting from both mathematical and economic point of view) will be further ignored. Non-trivial integral of this equation will determine the time path (or path of growth) of capital for the unit of effective work.
} 


$$
\begin{aligned}
& (1-\alpha) s-(1-\alpha)\left(\delta+n+\frac{\dot{A}(t)}{A(t)}\right) C(t) e^{-(1-\alpha)(\delta+n) t}(A(t))^{\alpha-1}= \\
& \dot{C}(t) e^{-(1-\alpha)(\delta+n) t}(A(t))^{\alpha-1}+C(t)(\alpha-1)(\delta+n) e^{-(1-\alpha)(\delta+n) t}(A(t))^{\alpha-1}+ \\
& +C(t) e^{-(1-\alpha)(\delta+n) t}(\alpha-1)(A(t))^{\alpha-2} \dot{A}(t)
\end{aligned}
$$

Thus, and from the relations (3) - (5) we get:

$$
C(t)=(1-\alpha) s \int \exp ((1-\alpha)(\delta+n) t)\left(A_{0}-\theta \exp (-\lambda t)\right)^{1-\alpha} d t
$$

Selecting t so that the condition is met $^{3}$ :

$$
\lambda t=\tau \lambda+W(-\theta \lambda \exp (-\lambda \tau))
$$

we get $C(t)$ approximated to the form:

$$
C(t)=(1-\alpha) s \int \exp (t(1-\alpha)(n+\delta)) t^{1-\alpha} d t
$$

In addition (for $\omega=2-\alpha)$ by differentiating $\Gamma(\omega,(1-\omega)(n+\delta) t)$ we get $^{4}$ :

$$
\frac{d(\Gamma(\omega,(1-\omega)(n+\delta) t))}{d t}=e^{(\omega-1)(n+\delta) t} t^{\omega-1}(1-\omega)(n+\delta)^{\omega}
$$

From here we finally get:

$$
C(t)=s(\omega-1)^{2}((1-\beta)(\delta+n))^{-\omega} \Gamma(\omega,(1-\omega)(n+\delta) t)+C
$$

where $C>0$.

Hence, and from the relations (14) and (17), capital for the unit of effective work can be written as:

$$
k_{E}(t)=\left(e^{(1-\omega)(\delta+n) t}(A(t))^{\omega-1} s(\omega-1)^{2}((1-\beta)(\delta+n))^{-\omega}(\Gamma(\omega,(1-\omega)(n+\delta) t)+C)\right)^{\frac{1}{\omega-1}}
$$

Assuming that for the discussed problem the Cauchy boundary condition of takes the form $k_{E}(0)=k_{E 0} \geq 0$, the constant $C>0$ can be written as:

$$
C=\frac{k_{E 0}^{\beta-1}-(\tau-\theta)^{1-\beta} s A_{0}^{1-\alpha}(\beta-1)((1-\beta)(\delta+n))^{1-\beta} \Gamma(\beta, 0)}{(\tau-\theta)^{1-\beta}}
$$

\footnotetext{
${ }^{3}$ The function $W(z)$ denotes the special function of W-Lambert, i.e. the function which for the complex number $\mathrm{z}$ meets the relation: $z=W(z) \exp (W(z))$.

${ }^{4}$ The function $\Gamma(z)$ is a special gamma function, i.e. a function defined for any complex number as: $\Gamma(z)=\frac{1}{z} \prod_{n=1}^{\infty} \frac{\left(1+\frac{1}{n}\right)^{z}}{1+\frac{z}{n}}$.
} 
Thus, the integral of equation (13) is written as:

$$
\begin{aligned}
& k_{E}(t)=\left[s A_{0}^{1-\alpha}(\beta-1)((1-\beta)(\delta+n))^{1-\beta} \Gamma(\beta,(1-\beta)(n\right. \\
& +\delta) t)+ \\
& +\frac{k_{E 0}^{\beta-1}-(\tau-\theta)^{1-\beta} s A_{0}^{1-\alpha}(\beta-1)((1-\beta)(\delta+n))^{1-\beta} \Gamma(\beta, 0)}{(\tau-\theta)^{1-\beta}} \\
& \left.\left(e^{t(1-\beta \delta)}\left(\tau-\theta e^{-\lambda t}\right)^{1-\beta}\right)\right]^{\frac{1}{1-\alpha}}
\end{aligned}
$$

In addition, the product for the unit of effective work $\left(y_{E}(t)\right)$ is described by the equation:

$$
\begin{aligned}
y_{E}(t)= & \left\lfloor s A_{0}^{1-\alpha}(\beta-1)((1-\beta)(\delta+n))^{1-\beta} \Gamma(\beta,(1-\beta)(n+\delta) t)+\right. \\
& +\frac{k_{E 0}^{\beta-1}-(\tau-\theta)^{1-\beta} s A_{0}^{1-\alpha}(\beta-1)((1-\beta)(\delta+n))^{1-\beta} \Gamma(\beta, 0)}{(\tau-\theta)^{1-\beta}} . \\
& \left.\left(e^{t(1-\beta \delta)}\left(\tau-\theta e^{-\lambda t}\right)^{1-\beta}\right)\right]^{\frac{\alpha}{1-\alpha}}
\end{aligned}
$$

\section{Calibration of Model Parameters and Numerical Simulations}

Numerical simulations of the theoretical model presented in point 3 were conducted in two stages in one-hundred-year periods. In the first stage, the values of parameters of equations describing the shaping of the scientific and technological knowledge and the path of labor productivity growth were calibrated. In the second stage, numerical simulations of the above-mentioned paths were performed based on different scenarios regarding the investment rates and the technological progress rate. For the function describing the growth path of the scientific and technological knowledge base, the following conjunction was adopted:

$$
\begin{aligned}
& A_{0^{-}} \\
& \Theta=A_{2000} \\
& \hat{A_{0}}=A_{2100}
\end{aligned}
$$

where: $A_{2000}$ and $A_{2100}$ are (respectively) resources of scientific and technological knowledge in 2000 and 2100. In the study, the level of scientific and technological knowledge $A(t)$ in 2000 was normalized to unity, and the level for 2100 was determined based on the average annual technological progress rate assuming that $A(t)$ will be shaped in accordance with geometric progress. To this end, the 
production function (1) was used, assuming a constant rate of increase in scientific and technological knowledge $\frac{\dot{A}(t)}{A(t)}=g>0$, thus, we get:

$Y(t)=\tilde{A} e^{g t}(K(t))^{\alpha}(L(t))^{1-\alpha}$

Where $\tilde{A}>0$ means the level of scientific and technological knowledge in the period $t=1$.

By logarithmizing equation (22) we obtain:

$$
\ln (Y(t))=\ln (\tilde{A})+g t+\alpha \ln (K(t))+(1-\alpha) \ln (L(t))
$$

When subtracting, in equation (23), the items $\ln (L(t))$ one can go to dependencies:

$$
\ln (y(t))=\ln (\tilde{A})+g t+\alpha \ln (k(t))
$$

The equation (24) describes the log-linear relationship between labor productivity $y$ and the technological development $k$ and the rate of technological progress. In the next stage, based on panel data for Polish provinces taken from the Central Statistical Office for the years 2000-2015, the parameters of the following equation were estimated:

$$
\ln \left(y_{i t}\right)=\alpha_{0}+\alpha_{1} t+\alpha_{2} \ln \left(k_{i t}\right)
$$

where $y_{\mathrm{it}}$ is labor productivity in the $i$-th of the provinces $(\mathrm{i}=1,2, \ldots, 16)$ in year $t$ $(t=2000,2001, \ldots, 2015) ; k_{\mathrm{it}}$ is a technological development in the $i$-th province in year $t ; \alpha_{0}$ this is the logarithm of the total productivity of factors of production; $\alpha_{1}$ parameter determining technological progress; $\alpha_{2}$ flexibility of labor productivity in relation to technological development.

\begin{tabular}{|c|c|}
\hline Explanatory variable & $\begin{array}{c}\text { Values of estimated } \\
\text { parameters }\end{array}$ \\
\hline Constant & $\begin{array}{l}-32.0685 \\
(0.0000)\end{array}$ \\
\hline $\ln \left(k_{i t}\right)$ & $\begin{array}{c}0.2997 \\
(0.0000)\end{array}$ \\
\hline$T$ & $\begin{array}{c}0.0174 \\
(0.0000)\end{array}$ \\
\hline $\begin{array}{l}R^{2} \\
\text { Corr. } R^{2}\end{array}$ & $\begin{array}{l}0.8171 \\
0.8151\end{array}$ \\
\hline
\end{tabular}

Table 1

Estimated parameters of the equation (25)

Source: personal study

The level of significance was given in brackets. 
The estimation of the parameters of the equation (25) was made on the basis of the instrumental variables method using the Generalized Method of Moments. The estimates presented in table 1 show that the average flexibility of labor productivity in relation to technological development in Polish provinces in the years 2000-2015 was about 0.30 and the value of such flexibility was accepted for further numerical simulations (see also [8]). In addition, the average annual technological progress rate for this period was approx. $1.7 \%$. For this reason, in numerical simulations two variants were adopted regarding the formation of the $A(t)$ value. The first variant (called optimistic) assumes such level of $A(t)$ in 2100 that would be determined by the average annual technological progress rate consistent with the estimates, while the second variant (realistic) assumes an average annual growth of $1.5 \%$.

Figure 1 presents the growth paths of scientific and technological knowledge with the assumed variants. Assuming the first variant, where the level $A(t)$ in 2100 will be implied by an average annual technological progress equal to $1.7 \%$. Assuming such a scenario of shaping the scientific and technological knowledge, its value in 2100 in relation to 2000 will increase by 4.8 times.

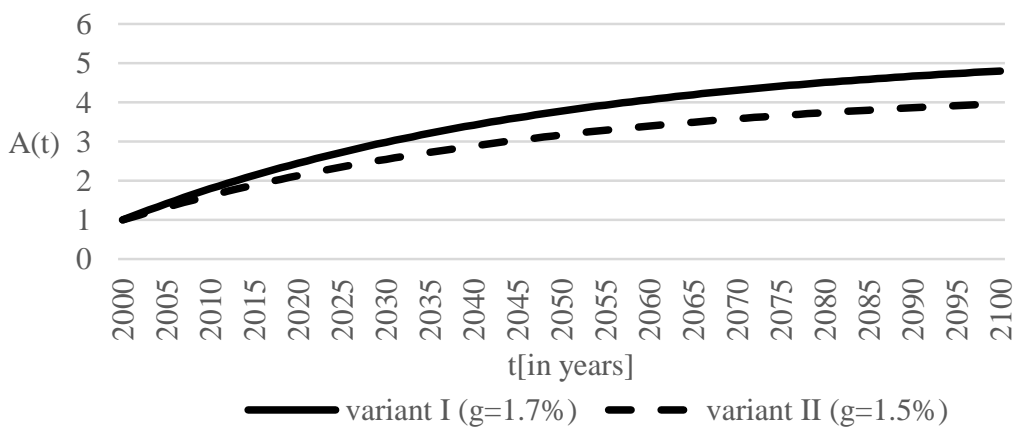

Figure 1

Trajectories of the scientific and technological knowledge in the adopted variants

Source: own study

\footnotetext{
${ }^{5}$ The Polish economy has undergone a system transformation from a centrally planned economy to a market economy. Almost 50 years of existence of a centrally planned economy in Poland generated significant technological delays (a technological gap) in relation to the economies of Western Europe. In the period 2000-2015, which was adopted to estimate the rate of technological progress, the Polish economy on the principle of technological convergence continued to reduce the technological gap. Thus, the estimated rate of technological progress may be overstated as it contains the effect of technological convergence. For this reason, in the realistic variants, the average annual rate of technological progress at the level of $1.5 \%$ was adopted.
} 
While accepting variant II an increase in the amount of scientific and technological knowledge in 2100 will be fourfold in comparison with 2000 .

In addition, in each of the variants considered, three scenarios regarding the investment rates were adopted. In the years 2000-2015, the average investment rate for the Polish economy was at the level of $19.8 \%$, and based on this average the authors assumed that this rate in the discussed time horizon would be equal to $20 \%$ assuming that it may deviate by 5 points rates. Bearing in mind the above, the variants regarding the investment rate were: $15 \%, 20 \%, 25 \%$. The growth rate of the number of employees was assumed at $1 \%$. In addition, based on the capital accumulation equation (2), the rate of depreciation of capital for the Polish economy was estimated. The equation describing the rate of depreciation of capital in discrete time is as follows:

$$
\delta=\frac{s K_{t}^{\alpha}-\Delta K_{t}}{K_{t}}
$$

Equation (26) assumes flexibility of labor productivity in relation to capital-labor ratio at the level of $30 \%$, and the investment rate at $20 \%$. Based on statistical data taken from the Central Statistical Office, regarding the development of physical capital in the Polish economy for the years 2000-2015, the rate of depreciation of capital at the level of $8.5 \%$ was estimated.

Table 2

Numerical simulations of labor productivity in various variants of the rate of technological progress and investment rates

\begin{tabular}{|c|c|c|c|c|c|c|}
\hline \multirow{2}{*}{$\begin{array}{c}\text { Simulation } \\
\text { period } \\
\text { (in years) }\end{array}$} & \multicolumn{3}{|c|}{ Variant I (g=1.7\%) } & \multicolumn{3}{c|}{ Variant II $(\mathrm{g}=1.5 \%)$} \\
\cline { 2 - 7 } & $\mathrm{s}=0.15$ & $\mathrm{~s}=0.2$ & $\mathrm{~s}=0.25$ & $\mathrm{~s}=0.15$ & $\mathrm{~s}=0.2$ & $\mathrm{~s}=0.25$ \\
\hline 2000 & 1 & 1 & 1 & 1 & 1 & 1 \\
\hline 2020 & 3.611 & 4.037 & 4.410 & 3.014 & 3.366 & 3.674 \\
\hline 2040 & 6.333 & 7.152 & 7.861 & 5.0181 & 5.665 & 6.225 \\
\hline 2060 & 8.498 & 9.609 & 10.571 & 6.589 & 7.451 & 8.196 \\
\hline 2080 & 10.071 & 11.391 & 12.534 & 7.725 & 8.738 & 9.614 \\
\hline 2100 & 11.172 & 12.638 & 13.906 & 8.518 & 9.636 & 10.603 \\
\hline
\end{tabular}

Source: Own study

Table 2 presents numerical simulations for a 100-year time horizon for the Polish economy. The following conclusions of the economic character can be drawn from the results of numerical simulations regarding the labor productivity growth paths. 
When assuming the first variant (see Fig. 2) regarding the rate of technological progress, and assuming that the economy will be characterized by a relatively low investment rate of $15 \%$, labor productivity in the discussed time horizon will increase more than eleven times. In the same scenario concerning technological progress, but assuming that investment rates will be at $20 \%$, labor productivity in the Polish economy will increase by about 12.5 times as compared to 2000 . With the first option, the highest increase in labor productivity would occur at the rate investment equal to $25 \%$ and this increase would be almost fourteen.

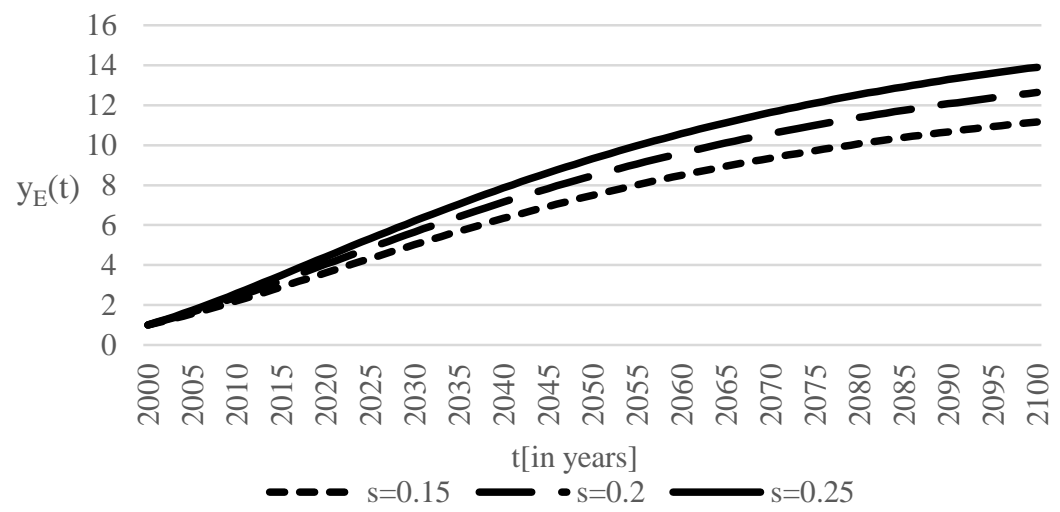

Figure 2

Labor productivity growth paths in various scenarios regarding investment rates and technological progress rate $\mathrm{g}=1.7 \%$

Source: Own study

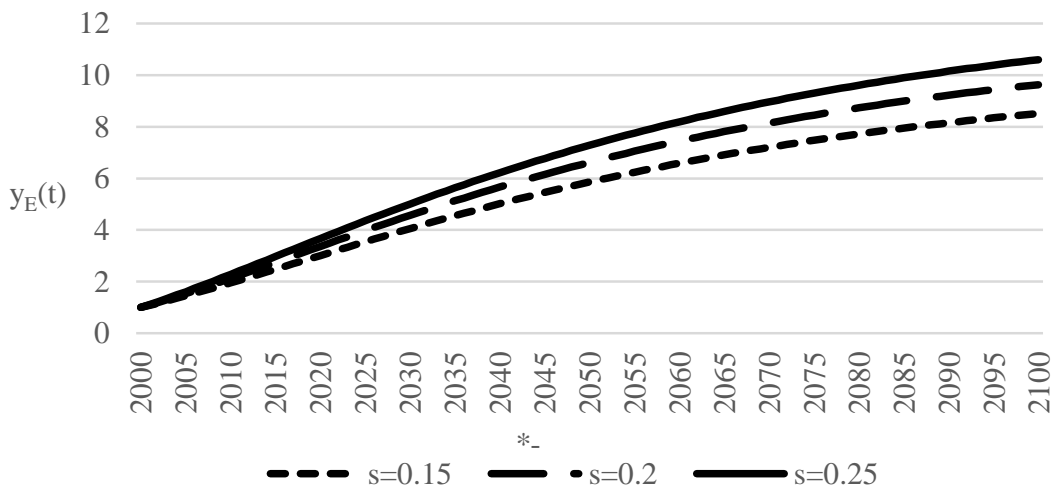

Figure 3

Labor productivity growth paths for various scenarios regarding investment rates and technological progress rate $\mathrm{g}=1.5 \%$

Source: Own study 
When assuming that the level of the scientific and technological knowledge in the year 2100 will increase by 4.8 times - the second variant and also assuming that the investment rate in the discussed time horizon will be $15 \%$, then the labor productivity will increase by about 8.5 times. However, with the same variant, assuming an investment rate of $20 \%$, the product per employee in the economy up to 2050 will increase by about 9.6 times. On the other hand, Figure 3 shows that with the second variant regarding the rate of technological progress, with an investment rate of $25 \%$, labor productivity in the years $2000-2050$ will increase by around 10.6 times.

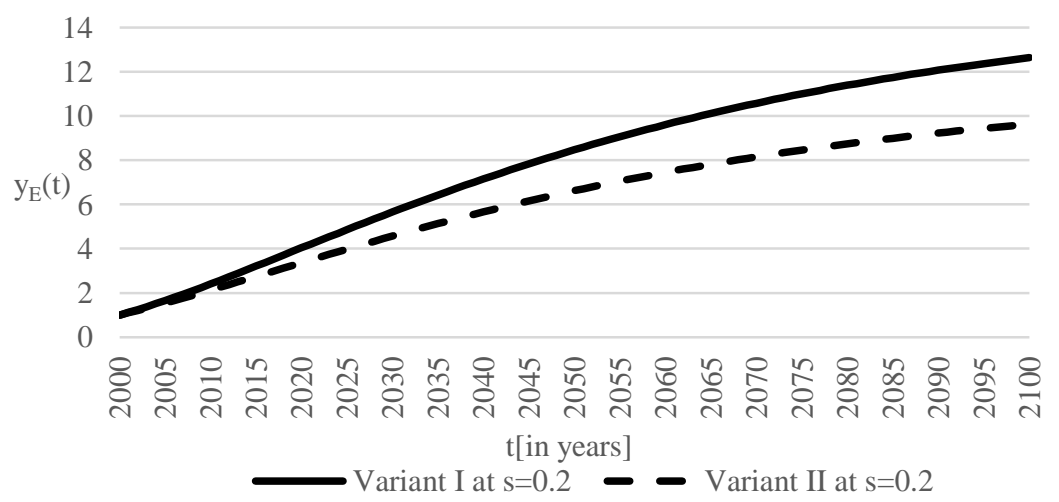

Figure 4

Compilation of labor productivity growth paths for different variants concerning the rate of technological progress and the investment rate $\mathrm{s}=20 \%$

Source: Own study

When comparing two options regarding the development of the scientific and technological knowledge in the horizon 2000-2100, it can be noticed that, for example, in the case of investment rates of $20 \%$ (see Fig. 4), labor productivity in 2100 will be approx. $30 \%$ higher than for the second variant.

\section{Conclusions}

The model of economic growth presented in the paper is a modification of the neo-classical Solow-Swan model (1956). In the model under consideration, the assumption of a constant rate of technological progress was abolished, thus assuming the path of growth of the scientific and technological knowledge resources changing exponentially to a permanent asymptote. This modification allowed taking into account, herein, certain scenarios concerning the shaping of the technological progress rate, thus obtaining various paths of growth of the scientific and technological knowledge. The study adopted two scenarios, regarding the technological progress rate, the first optimistic variant with a progress rate equal to $1.7 \%$ and (the second) realistic one for the rate equal to 
$1.5 \%$. Numerical simulations show that the scientific and technological knowledge in the Polish economy, 2000-2100 will increase about 4.8 times in the implementation of the optimistic variant, while the realistic variant has a lower growth rate of $400 \%$ in the year 2100 compared to the year 2000 .

For each of the variants regarding the development of the technological progress rate, three scenarios for the investment rate were selected. The following levels: $15 \%, 20 \%$, and $25 \%$ were assumed. The numerical simulations carried out for the investment rate of $15 \%$ allow noticing that depending on the adopted scenario, an 11 -fold increase in labor productivity (for the optimistic variant) and an 8.5-fold increase for the realistic variant is possible. With an investment rate of $20 \%$, an increase in labor productivity in the discussed time horizon was 12.6 times (in the optimistic variant) or 9.6 times (in the realistic variant). The highest increase in labor productivity was recorded at the investment rate of $25 \%$ and for the optimistic variant, it was 13.9 times, while for the realistic variant, it was 10.6 times.

\section{References}

[1] Aghion, P., Howitt, P.: A Model of Growth Through Creative Destruction, Econometrica, Vol. 60, March 1992

[2] Barro, R.: Economic Growth in a Cross Section Countries, Working Paper No. 3120, NBER, September 1989

[3] Baumol, W. J.: Entrepreneurship. Productive, Unproductive and Destructive, Journal of Political Economy, Vol. 98, 1990

[4] Bianca, C., Guerrini, L.: Existence of Limit Cycles in the Solow Model with Delayed-Logistic Population Growth, Scientific World Journal, 2014

[5] Cobb, C. W., Douglas, P. H.: A Theory of Production, American Economic Review, No. 18, 1928

[6] Conlisk, J.: A modified neoclassical growth model with endogenous technological change, The Southern Economic Journal, October 1967

[7] Dykas, P., Mentel, G., Misiak, T.: The Neoclassical Model of Economic Growth and Its Ability to Account for Demographic Forecast, Transformations in Business \& Economics, Vol. 17, No 2B(44B), 2018, pp. 684-700

[8] Filipowicz, K., Misiak, T., Tokarski, T.: Bipolar growth model with investment flows, Economics and Business Review, Vol. 2(16) No. 3, 2016

[9] Galor, O.: Unified Growth Theory, Princeton University Press, Princeton \& Oxford, 2011

[10] Grossman, G. M., Helpman, E.: Innovation and Growth in the Global Economy, MIT Press, Cambridge 1991 
[11] Guerrini, L.: A Closed Form Solution to the Ramsey Model with Logistic Population Growth, Economic Modeling, 27, 2010a, pp. 1178-1182

[12] Guerrini, L.: Logistic Population Change and the Mankiw-Romer-Weil Model, Applied Sciences, 12, 2010, pp. 96-101

[13] Guerrini, L.: The Solow-Swan Model with the Bounded Population Growth Rate, Journal of Mathematical Economics, 42, 2006, pp. 14-21

[14] Jones, Ch.: Time Series of Endogenous Growth Models, Quarterly Journal of Economics, Vol. 110, May 1995

[15] Kremer, M., Thomson, J.: Young Workers, Old Workers, and Convergence, NBER Working Papers, No. 4827, August 1994

[16] Kremer, M.: Population Growth and Technological Change. One Million B.C. to 1990, Quarterly Journal of Economics, Vol. 108, August 1993

[17] Mankiw, N. G., Romer, D., Wei, 1 D. N.: A Contribution to the Empirics of Economic Growth, Quarterly Journal of Economics, May 1992

[18] McCombie, J. S. L.: The Solow Residual, Technological Change and Aggregate Production Functions, Journal of Post Keynesian Economics, 23 (2), 2000, pp. 267-297

[19] McCombie, J. S. L.: What Does the Aggregate Production Function Tell Us? Second Thoughts on Solow's, Second Thoughts on Growth Theory, Journal of Post Keynesian Economics, 23 (4), 2001, pp. 589-615

[20] Romer, P. M.: Endogenous Technological Growth, Journal of Political Economy, Vol. 98, No. 5, 1990

[21] Romer, P. M.: Increasing Returns and Long-Run Growth, Journal of Political Economy, Vol. 94, No. 86, 1986

[22] Sinnathurai, V.: An Empirical Study on the Nexus of Poverty, GDP Growth, Dependency Ratio and Employment in Developing Countries, Journal of Competitiveness, Vol. 5, Issue 2, June 2013, pp. 67-82

[23] Solow, R. M.: A Contribution to the Theory of Economic Growth, Quarterly Journal of Economics, February 1956. s

[24] Sika, P., Vidová, J.: Interrelationship of migration and housing in Slovakia. Journal of International Studies, 10(3), 91-104, 2017

[25] Simionescu, M., Lazányi, K., Sopková, G., Dobeš, K., Balcerzak, A. P.: Determinants of Economic Growth in V4 Countries and Romania. Journal of Competitiveness, Vol. 9, Issue 1, pp. 103-116, 2017

[26] Sinicakova, M., Gavurova, B.: Single Monetary Policy versus Macroeconomic Fundamentals in Slovakia. Ekonomicky casopis, 65(2): 158-172, 2017 
[27] Soltes, V., Gavurova, B.: Modification of Performance Measurement System in the Intentions of Globalization Trends. Polish Journal of Management Studies, 11(2), 160-170, 2015

[28] Strielkowski, W., Tumanyan, Y., Kalyugina, S.: Labour Market Inclusion of International Protection Applicants and Beneficiaries, Economics and Sociology, Vol. 9, No 2, pp. 293-302, 2016

[29] Szilágyi, G. A.: Exploration Knowledge Sharing Networks Using Social Network Analysis Methods. Economics and Sociology, 10(3), 179-191, 2017

[30] Tkacova, A., Gavurova, B., Behun, M.: The Composite Leading Indicator for German Business Cycle. Journal of Competitiveness, Vol. 9, Issue 4, pp. 114-133, 2017

[31] Tokarski, T.: Ekonomia matematyczna. Modele makroekonomiczne, Polskie Wydawnictwo Ekonomiczne, Warszawa 2011

[32] Tokarski, T.: Matematyczne modele wzrostu gospodarczego (ujęcie neoklasyczne), Wydawnictwo Uniwersytetu Jagiellońskiego, Kraków 2009 